\title{
Objective evaluation of vision quality in pseudophakic patients with posterior capsular opacification using double-pass retinal imaging
}

\author{
Avaliação objetiva da qualidade da visão em pacientes pseudofácicos com \\ opacificação capsular posterior pelo método de dupla passagem de luz
}

\author{
Jake C. McMillin,2, Karolinne M. Rocha1,2, Eliza L. Barnwell1, Jorge S. Haddad², George O. Waring IV³ \\ 1. Medical University of South Carolina, Charleston, SC, USA. \\ 2. Storm Eye Institute, Medical University of South Carolina, Charleston, SC, USA \\ 3. Waring Vision Institute, Mount Pleasant, SC, USA.
}

\begin{abstract}
I Purpose: The purpose of this study was to objectively assess the optical vision quality of patients before and after Nd:YAG capsulotomy for posterior capsular opacification using a double-pass retinal imaging system. Methods: We retrospectively analyzed the data from 26 pseudophakic eyes with posterior capsular opacification that underwent Nd:YAG capsulotomy. The objective scatter indices, modulation transfer function cutoff frequencies, Strehl ratios, and $\log M A R$ corrected distance visual acuities were assessed before and after YAG capsulotomy with a double-pass retinal imaging system (OQAS II, Visiometrics, Spain). We also analyzed data from a subgroup of 10 patients with pre-YAG corrected distance visual acuity of $0.10 \log$ MAR (20/25) or better. Results: Vision quality indices improved in all 26 eyes, resulting in a statistically significant improvement in the corrected distance visual acuity $(p=0.007)$, objective scatter index $(\mathrm{p}=0.001)$, modulation transfer function cutoff frequency $(p=0.001)$, and Strehl ratio $(p=0.020)$. The overall mean improvements included $0.12 \pm 0.04 \operatorname{logMAR}$ for corrected distance visual acuity, $2.84 \pm 0.76$ for objective scatter index, $12.29 \pm 2.77$ for modulation transfer function cutoff frequency, and $0.06 \pm 0.03$ for Strehl ratio. Our sub-analysis of 10 eyes
\end{abstract}

Submitted for publication: July 20, 2018

Accepted for publication: September 20, 2018

Funding: Support provided in part by an unrestricted grant from the South Carolina Lions Club.

Disclosure of potential conflicts of interest: None of the authors have any potentia conflicts of interest to disclose.

Corresponding author: Jorge Selem Haddad.

Storm Eye Institute - 167 Ashley Ave., Charleston, SC 29425

E-mail: Jshaddad2@hotmail.com

Approved by the following research ethics committee: The study was exempt from human subjects regulation by the institutional review board as per Guidance 45 CFR 46.101(b) (5) from the U.S. office for Human Research Protections. with 0.10 logMAR (20/25) corrected distance visual acuity or better also showed a statistically significant improvement in the mean objective scatter index $(0.76 \pm 16 ; p=0.001)$, resulting in approximately $35 \%$ decrease in intraocular light scatter. Conclusions: The objective vision quality measurements as assessed by the double-pass retinal imaging system showed a significant improvement after YAG capsulotomy. This suggests that the objective scatter index improves after YAG capsulotomy, even in eyes with pre-YAG 0.10 logMAR (Snellen 20/25) corrected distance visual acuity or better.

Keywords: Capsule opacification; Cataract extraction; Posterior capsulotomy; Visual acuity; Lasers

RESUMO I Objetivo: Avaliar objetivamente a qualidade da visão óptica antes e depois da capsulotomia com $\mathrm{Nd}$ : YAG, obtida por imagem pelo metodo de dupla passagem de luz em pacientes com opacificação capsular posterior. Método: Análise retrospectiva de 26 olhos pseudofácicos com opacificação capsular posterior visualmente significativa, que foram submetidos à capsulotomia de $\mathrm{Nd}$ : YAG. O índice de dispersão objetiva, a função de transferência de modulação, a relação de Strehl e a acuidade visual à distância corrigida foram avaliados antes e após a capsulotomia com YAG usando o dupla passagem de luz (OQAS II, Visiometrics, Espanha). Também foi analisado um subgrupo de pacientes com acuidade visual à distância corrigida pré-YAG de 0,10 logMAR (20/25) ou melhor. Resultados: Os índices de qualidade da visão melhoraram em todos os 26 olhos, resultando em uma melhora estatisticamente significativa na acuidade visual à distância corrigida $(p=0,007)$, índice de dispersão objetiva $(p=0,001)$, função de transferência de modulação $(p=0,001)$ e relação de Strehl $(p=0,020)$. A melhora média na acuidade visual à distância corrigida foi de 0,12 $\pm 0,04 \log M A R$, no índice de dispersão objetiva foi de 2,84 $\pm 0,76$, no função de transferência de modulação foi de 12,29 \pm 2,77 e na razão de Strehl foi de 0,06 $\pm 0,03$ em todos os olhos. Sub-análise de 10 olhos com 0.10 logMAR (20/25) acuidade visual à distância corrigida ou melhor 
também mostrou uma melhora estatisticamente significativa no índice de dispersão objetiva $(\mathrm{p}=0,001)$. A melhora média no OSI foi de $0,76 \pm 16$, uma diminuição de $35 \%$ na dispersão da luz intraocular. Conclusões: A qualidade da visão avaliada pelo dupla passagem de luz mostra uma melhora significativa nas medidas objetivas da qualidade da visão após a capsulotomia do YAG. $\mathrm{O}$ índice de dispersão objetiva melhora após a capsulotomia YAG, mesmo em olhos com acuidade visual à distância corrigida pré-YAG de 0,10 logMAR (Snellen 20/25) ou melhor.

Descritores: Opacificação da cápsula; Extração de catarata; Capsulotomia posterior; Acuidade visual; Lasers

\section{INTRODUCTION}

Posterior capsular opacification (PCO) is the most common late complication of cataract surgery associated with implantation of posterior chamber intraocular lenses (PClOLs) ${ }^{(1)}$. More than a quarter of patients develop visually significant PCOs within 5 years of cataract surgery ${ }^{(1)}$. The underlying pathophysiological PCO mechanism stems from the intrinsic potential of retained lenticular epithelial cells to migrate and proliferate over the posterior capsule and into the visual $\mathrm{axis}^{(2)}$. The growth of these cells in the visual axis may cause decreased contrast sensitivity, visual acuity (VA), and worsening glare ${ }^{(3,4)}$. VA and contrast sensitivity with and without a glare source are the most common subjective metrics for grading PCO severity ${ }^{(5-7)}$.

Forward light scatter has also been proposed as a mechanism to evaluate visual function in patients with visually significant $\mathrm{PCO}^{(7)}$. Forward light scatter detects the light that does not come into focus on the retina because of aberrations within the optical system, resulting in halos, glares, and difficulty during driving under scotopic conditions ${ }^{(8)}$.

Double-pass retinal imaging (DPRI) can be used to analyze the point-spread function (PSF) directly from the retinal image; it is a validated and reproducible technology designed to evaluate forward light scatter through the optical system ${ }^{(9-11)}$. The method enables mathematical reconstruction of the entire optical system allowing the clinician to "see" images as they are cast onto the patient's retina and perceived by the patient ${ }^{(11)}$. This objective representation of retinal image quality does not require any response from the patient, unlike earlier developed methods.

A commercially available double-pass imaging system (HD analyzer, Visiometrics, Barcelona, Spain) provides objective metrics to describe the optical quality-objective scatter index (OSI), modulation transfer function cutoff frequency (MTF), and Strehl ratio. The OSI derived from the PSF is a novel measurement quantifying forward light scatter as an objective value that can be followed over time. This metric compares the intensity recorded on the peripheral PSF parts to its very central peak ${ }^{(9,11)}$. PSF and OSI have previously been used to evaluate and grade cataracts ${ }^{(10,12)}$. The modulation transfer function (MTF) cutoff frequency is the maximum spatial frequency that can be resolved by an optical system, and it correlates directly with the VA. The Strehl ratio reflects the maximum PSF central luminance versus that in a perfect ocular system without aberrations. The values range from 0 to 1 , where 1 indicates a perfect optical system $^{(9)}$. Clinically, these DPRI values provide an objective, reliable evaluation of visual quality that may potentially be useful to physicians for assessing PCO grades to help with treatment decisions.

We aimed to analyze the objective metrics of retinal image quality by DPRI in patients with PCO before and after Neodymium Yttrium Aluminum Garnet (Nd:YAG) capsulotomy. In addition, we sought to study the visual quality in patients with night vision symptoms (glare and halos) and in those with relatively well-preserved corrected distance VA (CDVA) of 20/25 (0.1 logMAR) or better.

\section{METHODS}

We created a retrospective chart review for Nd:YAG capsulotomies performed between August 2015 and August 2016. Two surgeons with similar practice habits performed all the procedures in this group of patients at a single refractive surgery clinic belonging to a large academic practice. We extracted data and diagnostic images from the electronic medical records and the imaging software in such a way that patients could not be identified directly or indirectly through identifiers. Therefore, the institutional review board exempted the study from human subjects' regulation as per Guidance 45 CFR 46.101(b) (5) from the U.S. office for Human Research Protections.

After reviewing all Nd:YAG capsulotomies, we included patients with a complete ophthalmic examination and with CDVA and DPRI data before and after the $\mathrm{Nd}$ :YAG capsulotomy. We excluded patients with ocular pathologies deemed significant to create ocular scatters other than PCO, including moderate and severe keratoconjunctivitis sicca, corneal dystrophies, corneal scars, dense vitreous opacities, or a history of uveitis, glaucoma, macular degeneration, diabetic retinopathy, or anterior capsular contraction. 
Certified ophthalmic technicians in an ophthalmic clinic obtained DPRI (HD Analyzer, Visiometrics, Barcelona, Spain) results. Images were obtained with the patients' manifest refractions programmed into the imaging software. During the first pass of this method, a point source created by a diode laser beam at $780 \mathrm{~nm}$ enters the eye and is conjugated on the retina, to then undergo a second pass from the retina to a recording device ${ }^{(9)}$. The instrument calculates indices of visual quality described earlier (OSIs, MTF cutoff frequencies, and Strehl ratios) based on the PSF measurements from means of six acquisitions. Figure 1 shows an example slit-lamp examination for subjective PCO grades $1-3^{(13,14)}$ and their corresponding PSF and OSI obtained by the DPRI system. We compared postprocedural images to those obtained before the procedure to ensure that the manifest refractions used to collect the images were within 0.5 diopters of the spherical equivalent (SE) of the original manifest refraction and excluded SEs that were outside of this range.

We converted Snellen VA to the logMAR scale for statistical analysis. The data were analyzed as continuous

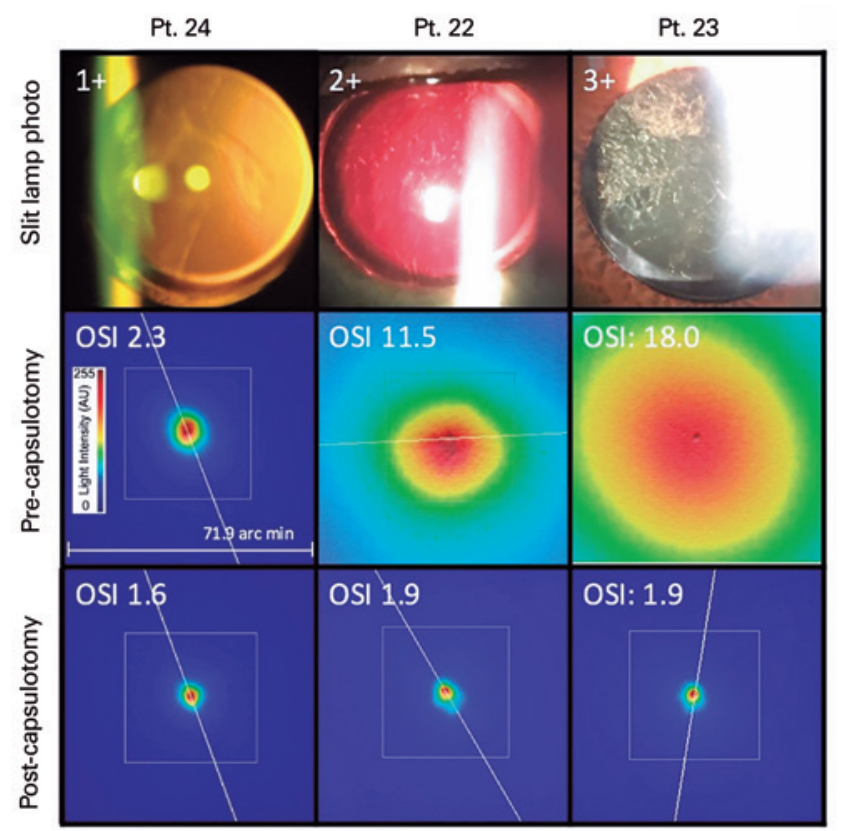

Figure 1. (Top Row) Slit lamp photos displayed by retro-illumination of subjective, clinically graded PCOs. (Middle Row) Two-dimensional point-spread function plots derived from double-pass retinal imaging of pre-capsulotomy posterior capsular opacities, the objective scatter index values are presented in the top left of each panel. The scatter axis is displayed by a gray line. Colors represent the relative intensity of light scatter. (Bottom Row) Post-capsulotomy two-dimensional point-spread function plots displayed in the same fashion with the objective scatter index displayed in the top left corner of each panel. variables using a paired student $t$-test using the SPSS software (SPSS, Chicago, IL). We considered statistical significance for $p$-values of $<0.05$. Data are reported as mean values \pm standard error of the mean (SEM).

\section{RESULTS}

Our analysis included 26 eyes, with a mean age of $69 \pm 1.38$ years. Clinicians diagnosed PCOs grading them as $1+$ in 4 eyes, $2+$ in 14 eyes, and $3+$ in 8 eyes. The mean time between acquisition of the double-pass images was 45.7 days. Table 1 displays the patient demographics.

The mean pre- and post-capsulotomy values are displayed in Table 2 . We observed statistically significant improvements in all vision quality indices according to the paired student $t$-test. The CDVA improved by a mean of $0.12 \pm 0.04(p=0.007)$, the OSI had a mean decrease of $2.84 \pm 0.76(p=0.001)$, the MTF cutoff frequency increased by $12.29 \pm 2.77(p<0.001)$, and the Strehl ratio increased by $0.06 \pm 0.03(p=0.020)$. The decrease in OSI correlates with a $62 \%$ decrease in light scatter and an approximate 1-line improvement in the Snellen VA scale. The MTF cutoff frequency and Strehl ratio also showed statistically significant increases, indicating improved contrast sensitivity.

We categorized patients into two groups to perform sub-analyses; group 1 consisted of 10 symptomatic patients with pre-YAG VA of 0.10 logMAR (20/25 Snellen) or better, and group 2 consisted of the remainder 16 patients with pre-YAG VA worse than 0.10 logMAR (20/25 Snellen). The comparison of changes in acuity and visual quality indices from pre- to post-capsulotomy values for each subgroup are illustrated in figures 2-4.

The eyes of patients in group 1 with pre-YAG Snellen CDVA $20 / 25$ or better ( $\leq 0.10 \log M A R)$ had a mean CDVA of $0.03 \pm 0.02 \operatorname{logMAR}(20 / 21$ Snellen). Table 3 shows the mean changes in acuity and visual quality metrics for this group. We found a statistically significant improvement in OSI with a mean decrease in light scatter of $0.76 \pm 0.16(p=0.001)$, representing a $35 \%$ decrease in intraocular light scatter despite an initial Snellen VA of $20 / 25$ or better. Although the MTF cutoff frequencies and Strehl ratios all tended to improve, the differences did not reach statistical significance. The CDVA did not show a clinically significant improvement; however, as illustrated in figure 5 , there was little room for improvement in these patients.

The eyes of patients in group 2 with pre-YAG CDVA worse than 20/25 (>0.10 logMAR) had a mean pre-YAG 
Table 1. Patient characteristics

\begin{tabular}{lccc}
\hline Characteristics & All Eyes & $\begin{array}{c}\text { Group 1 } \mathbf{1} \text { (0.10 } \\
\text { logMAR, 20/25 or } \\
\text { better) }\end{array}$ & $\begin{array}{c}\text { Group 2 (>0.10 } \\
\text { logMAR, worse } \\
\text { than 20/25) }\end{array}$ \\
\hline Eyes (n) & 26 & 10 & 16 \\
Mean age (y) & $69 \pm 1.38$ & $68.5 \pm 1.19$ & $68.4 \pm 2.14$ \\
Male sex, $\mathrm{n}(\%)$ & $13(50 \%)$ & $4(40 \%)$ & $9(56 \%)$ \\
Eye & 13 OD, 13 OS & 6 OD, 4 OS & 7 OD, 9 OS \\
$\begin{array}{l}\text { Mean time to } \\
\text { follow-up (days) }\end{array}$ & $45.7 \pm 6.61$ & $46.0 \pm 12.82$ & $45.4 \pm 7.87$ \\
Grade of PCO & & & \\
$1+$ & 4 & 2 & 2 \\
$2+$ & 14 & 7 & 7 \\
$3+$ & 8 & 1 & 7 \\
\hline
\end{tabular}

$\mathrm{PCO}=$ posterior capsule opacification.

Error reported as standard error of the mean (SEM).

Table 2. Changes between pre- and post-Nd: Yag measurements

\begin{tabular}{lccccc}
\hline Parameter & Pre-YAG & Post YAG & \multicolumn{1}{l}{ Change } & p value \\
\hline CDVA & $0.22 \pm 0.04$ & $0.09 \pm 0.03$ & $(-)$ & $0.12 \pm 0.04$ & $0.007^{*}$ \\
OSI & $4.59 \pm 0.81$ & $1.75 \pm 0.19$ & $(-)$ & $2.84 \pm 0.76$ & $0.001^{*}$ \\
$\begin{array}{l}\text { MTF cutoff } \\
\text { frequency (cpd) }\end{array}$ & $18.94 \pm 2.37$ & $31.23 \pm 1.88$ & $(+) 12.29 \pm 2.77$ & $0.001^{*}$ \\
Strehl ratio & $0.11 \pm 0.01$ & $0.17 \pm 0.03$ & $(+)$ & $0.06 \pm 0.03$ & $0.020^{*}$ \\
\hline
\end{tabular}

$\mathrm{CDVA}=$ corrected distance visual acuity; $\mathrm{OSI}=$ objective scatter index; $\mathrm{MTF}=$ modulation transfer function; $\mathrm{cpd}=$ cycles per degree.

Error reported as standard error of the mean (SEM).

*statistically significant at $\mathrm{p}<0.05$.

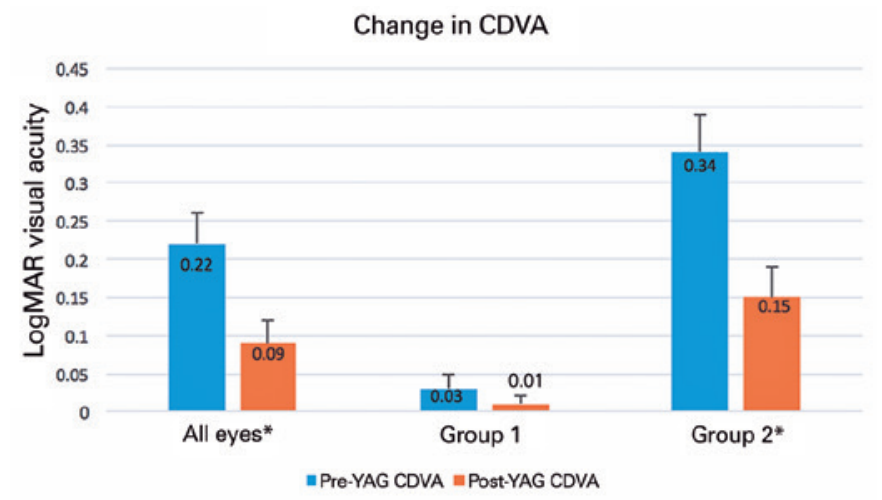

Figure 2. Mean changes in corrected distance visual acuity (CDVA) after

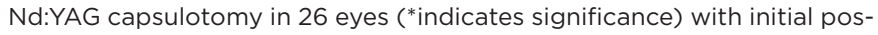
terior capsule opacification. Subject eyes are grouped by All eyes $(n=26)$, Group 1 (20/25 or better, N=9), or Group 2 (less than 20/25 CDVA, N=16). Error bars represent standard error of the mean (SEM).

CDVA of $0.34 \pm 0.05 \log$ MAR (20/44 Snellen). Table 3 shows the mean changes in visual quality metrics post-capsulotomy for this group. In contrast to group 1 , group 2 showed a significant improvement in all four metrics of vision quality, not just in OSI. The CDVA improved by

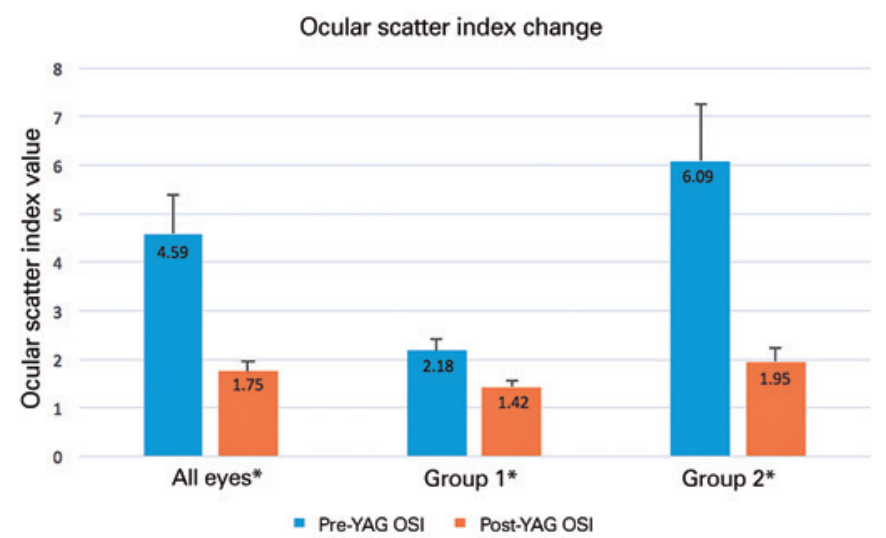

Figure 3. Mean changes in objective scatter index (OSI) after Nd:YAG capsulotomy in 26 eyes (*indicates significance) with initial posterior capsule opacification. Subject eyes were grouped into an All eyes group $(n=26)$, Group 1 (20/25 or better, N=9), or Group 2 (less than 2O/25 CDVA, N=16). Error bars represent standard error of the mean (SEM).

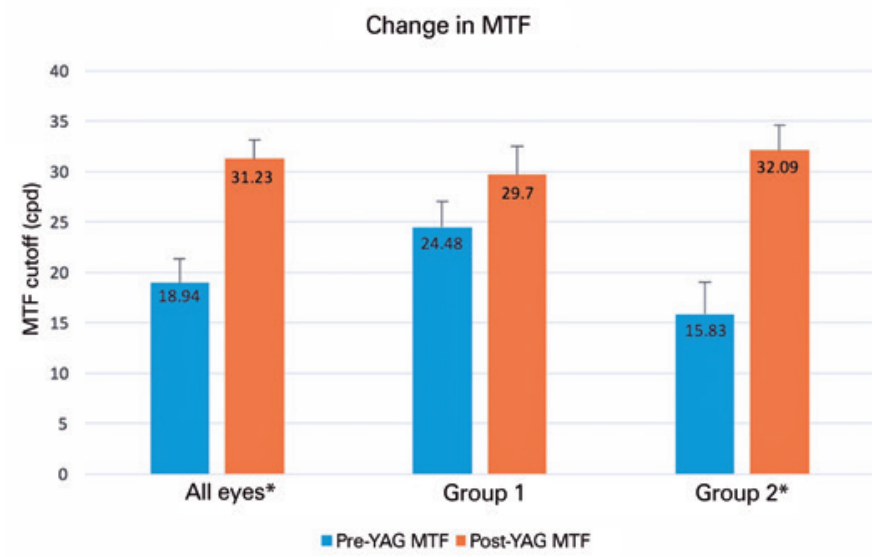

Figure 4. Average changes in modulation transfer function (MTF) after $\mathrm{Nd}$ :YAG capsulotomy in 26 eyes (*indicates significance) with posterior capsule opacification. Subject eyes are grouped into an All eyes group $(n=26)$, Group 1 (2O/25 or better, $N=9$ ), or Group 2 (less than 20/25 CDVA $\mathrm{N}=16$ ). Error bars represent standard error of the mean (SEM).

a mean of $0.18 \pm 0.06 \log M A R(p=0.009)$, which correlates with approximately 1.5 lines on the Snellen acuity chart. The OSI showed a $68 \%$ mean decrease in intraocular scatter with a mean decrease of $4.14 \pm 0.28(p=0.002)$. Finally, the MTF cutoff frequency increased by a mean of $16.27 \pm 3.77(p=0.001)$, and the Strehl ratio increased by $0.05 \pm 0.01(p=0.001)$.

\section{DISCUSSION}

In this study, CDVA, OSI, MTF cutoff frequency, and Strehl ratio demonstrated statistically significant im- 
Table 3. Changes in parameters between pre- and post-Nd: Yag according to groups

\begin{tabular}{|c|c|c|c|c|}
\hline Parameter & Pre-YAG & Post YAG & Change & $p$ value \\
\hline & \multicolumn{4}{|c|}{ Group 1} \\
\hline CDVA & $0.03 \pm 0.02$ & $0.01 \pm 0.01$ & $(-) .02 \pm 0.02$ & 0.343 \\
\hline OSI & $2.18 \pm 0.24$ & $1.42 \pm 0.15$ & $(-) 0.76 \pm 0.16$ & $0.001^{*}$ \\
\hline MTF cutoff frequency (cpd) & $24.48 \pm 2.57$ & $29.70 \pm 2.77$ & $(+) 5.22 \pm 3.02$ & 0.122 \\
\hline \multirow[t]{2}{*}{ Strehl ratio } & $0.13 \pm 0.02$ & $0.21 \pm 0.01$ & $(-) 0.08 \pm 0.07$ & 0.282 \\
\hline & \multicolumn{4}{|c|}{ Group 2} \\
\hline CDVA & $0.34 \pm 0.05$ & $0.15 \pm 0.04$ & $(-) 0.18 \pm 0.06$ & $0.009 *$ \\
\hline OSI & $6.09 \pm 1.16$ & $1.95 \pm 0.29$ & $(-) 4.14 \pm 0.28$ & $0.002 *$ \\
\hline MTF cutoff frequency (cpd) & $15.83 \pm 3.17$ & $32.09 \pm 2.48$ & $(+) 16.27 \pm 3.77$ & $0.001^{*}$ \\
\hline Strehl ratio & $0.10 \pm 0.01$ & $0.15 \pm 0.01$ & $(+) 0.05 \pm 0.01$ & $0.001 *$ \\
\hline
\end{tabular}

$\mathrm{CDVA}=$ corrected distance visual acuity; OSI= objective scatter index; MTF= modulation transfer function; $\mathrm{cpd}=\mathrm{cycles}$ per degree.

Error reported as Standard Error of the Mean (SEM).

*Statistically significant at $\mathrm{p}<0.05$

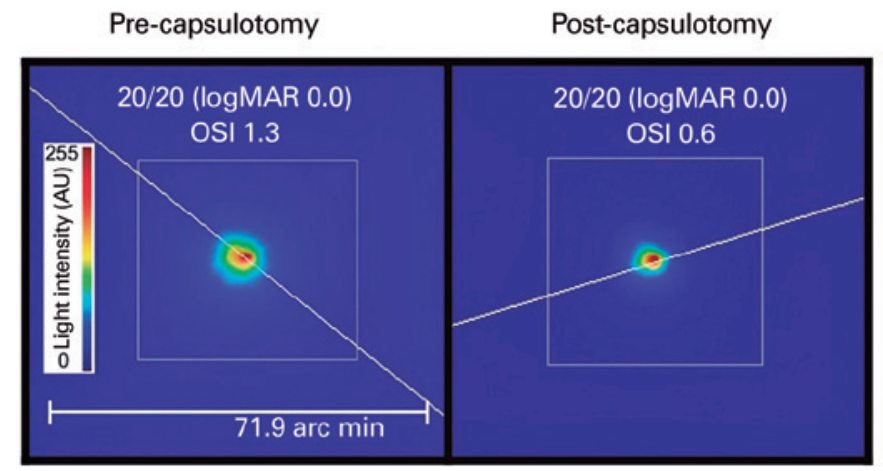

Figure 5. Post-capsulotomy two-dimensional point-spread function plots displayed with changes in the objective scatter index in a 20/20 patient.

provements after Nd:YAG laser posterior capsulotomy. These results indicate a DPRI system can be used to detect CDVA and perform objective vision quality measurements after Nd:YAG capsulotomy in patients with decreased vision quality due to PCO. Similar studies using a compensation comparison method have also shown that the CDVA and stray light values improved after Nd:YAG capsulotomy ${ }^{(15,16)}$. Our study confirmed these findings with the intraocular scatter measurements obtained as OSls. Moreover, the data for all eyes showed statistically significant improvements in MTF cutoff frequencies and Strehl ratios, indicating that contrast sensitivity and image quality also improve after Nd:YAG capsulotomy.

Patients with good initial VA (0.10 logMAR, 20/25 or better) but with symptoms of decreased vision quality (glare and halos) also showed a statistically significant improvement in OSls after capsulotomy. A similar study on eyes with good initial VA (20/20) showed significant improvements in intraocular stray light using the compensation comparison method ${ }^{(8)}$. We have strengthened this evidence with our DPRI findings showing OSIs and thus removing subjectivity from the data acquisition process. Our findings agree with those in reports indicating that intraocular light scatter may be a better marker of early visual function decline from PCO than VA alone ${ }^{(17)}$. In this study, we observed a trend toward improvements in MTF cutoff frequency and Strehl ratio in group 1 (20/25 or better Snellen acuity), although not statistically significant. However, in group 2 (worse than 20/25 acuity), the MTF cutoff frequency and Strehl ratio remained significantly different. One explanation for this may be the small sample size with insufficient power to determine whether the MTF cutoff frequency and Strehl ratio were affected in patients with good VA in the early PCO stages.

DPRI has been used to evaluate cataracts and proven useful for determining their impact on vision before making surgical decisions ${ }^{(18)}$. Our study demonstrates the use of DPRI for evaluating patients with PCO. DPRI provides repeatable and reproducible measurements of visual function ${ }^{(9-11)}$. It can be performed quickly in a clinical setting by trained ophthalmic technicians and incorporated into the workflow of a busy clinic.

Patients often develop vision complaints after cataract surgery irrespective of their VA. The decision to perform a laser capsulotomy in patients with reduced VA is straightforward. However, in patients with very good CDVA but vision complaints, whether Nd:YAG capsulotomy will 
address patient symptoms may be unclear. Our study shows a significant improvement in intraocular scatter in patients with good pre-YAG CDVA and suggests that YAG capsulotomy may improve vision quality in patients with relatively good pre-YAG CDVA and an otherwise typical clinical examination. DPRI may be a useful tool for understanding vision complaints in patients with PCO. In addition, laser capsulotomy improves the quality of vision based on multiple objective measurements.

\section{REFERENCES}

1. Schaumberg DA, Dana MR, Christen WG, Glynn RJ. A systematic overview of the incidence of posterior capsule opacification. Ophthalmology. 1998;105(7):1213-21.

2. Apple DJ, Solomon KD, Tetz MR, Assia El, Holland EY, Legler UF, et al. Posterior capsule opacification. Surv Ophthalmol. 1992; 37(2):73-116.

3. Claesson M, Klaren L, Beckman C, Sjostrand J. Glare and contrast sensitivity before and after Nd:YAG laser capsulotomy. Acta Ophthalmol (Copenh). 1994;72(1):27-32.

4. Daynes T, Spencer TS, Doan K, Mamalis N, Olson RJ. Three-year clinical comparison of 3-piece AcrySof and SI-40 silicone intraocular lenses. J Cataract Refract Surg. 2002;28(7):1124-9.

5. Wasserman EL, Axt JC, Sheets JH. Neodymium: YAG laser posterior capsulotomy. J Am Intraocul Implant Soc. 1985;11(3):245-8.

6. Pennos A, Ginis H, Arias A, Christaras D, Artal P. Performance of a differential contrast sensitivity method to measure intraocular scattering. Biomed Opt Express. 2017;8(3):1382-9.

7. Sunderraj P, Villada JR, Joyce PW, Watson A. Glare testing in pseudophakes with posterior capsule opacification. Eye (Lond). 1992;6 (Pt 4):411-3.

8. Yotsukura E, Torii H, Saiki M, Negishi K, Tsubota K. Effect of neodymium:YAG laser capsulotomy on visual function in patients with posterior capsule opacification and good visual acuity. J Cataract Refract Surg. 2016;42(3):399-404.

9. Saad A, Saab M, Gatinel D. Repeatability of measurements with a double-pass system. J Cataract Refract Surg. 2010;36(1):28-33.

10. Artal P, Benito A, Perez GM, Alcon E, De Casas A, Pujol J, et al. An objective scatter index based on double-pass retinal images of a point source to classify cataracts. PLoS One. 2011;6(2):e16823.

11. Leonard AP, Gardner SD, Rocha KM, Zeldin ER, Tremblay DM, Waring GO. Double-pass retina point imaging for the evaluation of optical light scatter, retinal image quality, and staging of keratoconus. J Refract Surg. 2016;32(11):760-5.

12. Pan AP, Wang QM, Huang F, Huang JH, Bao FJ, Yu AY. Correlation among lens opacities classification system Ill grading, visual function index-14, pentacam nucleus staging, and objective scatter index for cataract assessment. Am J Ophthalmol. 2015;159(2): 241-7e2.

13. Tetz MR, Nimsgern C. Posterior capsule opacification. Part 2: Clinical findings. J Cataract Refract Surg. 1999;25(12):1662-74.

14. Findl O, Buehl W, Menapace R, Georgopoulos M, Rainer G, Siegl H, et al. Comparison of 4 methods for quantifying posterior capsule opacification. J Cataract Refract Surg. 2003;29(1):106-11.

15. Montenegro GA, Marvan P, Dexl A, Pico A, Canut MI, Grabner G, et al. Posterior capsule opacification assessment and factors that influence visual quality after posterior capsulotomy. Am J Ophthalmol. 2010;150(2):248-53.

16. van Bree MC, Zijlmans BL, van den Berg T]. Effect of neodymium:YAG laser capsulotomy on retinal straylight values in patients with posterior capsule opacification. J Cataract Refract Surg. 2008;34(10): 1681-6.

17. van Bree MC, van den Berg T], Zijlmans BL. Posterior capsule opacification severity, assessed with straylight measurement, as main indicator of early visual function deterioration. Ophthalmology. 2013;120(1):20-33.

18. Galliot F, Patel SR, Cochener B. Objective Scatter Index: working toward a new quantification of cataract? J Refract Surg. 2016; 32(2):96-102. 